\title{
Placebos and Medical Education
}

\author{
Amir Raz*, Daniella Guindi
}

\section{THE PLACEBO CHALLENGE}

Placebos are ubiquitous, counterintuitive, topical, and germane to medical science (1). Current scientific understanding about placebos, however, is sparse, fraught with debates and even explicit confusion (2-4). Whether one subscribes to placebo phobia or placebo mania (5), the domain of placebos draws on definitions, concepts, and paradigms that often baffle not just the general public, but the greater medical community (3). Thus, many modern physicians find placebos difficult to swallow or prescribe for others (6). As we discuss separately in this issue, ethical considerations complicate administration of placebos in clinical settings (7-9). Ethics aside, however, practitioners seem unclear even about fundamental concepts in the science of placebos, including the difference between placebo effect and placebo response (10). The platitudes health care professionals utter about placebos in personal communications and over cocktails provide ample evidence for this trend. The bright McGill University fourth-year medical students who attended my Placebos in Medicine class were products of this dynamic. (McGill Medical School offers Placebos in Medicine as an elective component to a Medicine and Society core course).

Medical students receive little education about placebos. This lacuna may well explain why the medical community continues to entertain an incoherent understanding of the placebo effect, largely considering it a sham effect, albeit one coupled with a powerful physiology (11). Furthermore, most contemporary medical students obfuscate the little they know of

*To whom correspondence should be addressed:

Amir Raz, Ph.D., ABPH

McGill-JGH-ICFP-MNI Canada Research Chair

4333 Cote Ste Catherine Rd.

Montreal, Quebec H3T 1E4

Canada

Tel: 514-340-8210 ; Fax: 514-340-8124

E-mail: amir.raz@mcgill.ca placebos with what they learn in "physicianship" (i.e., courses focusing on the "softer" issues of medicine, such as bed-side manner). Speciously, they seem to view placebos through the narrow lens of grooming and dressing well for the clinic, smiling at patients, and maintaining a cheerful attitude. Consequently, tomorrow's clinicians expect placebos to wield a minor effect, if any. Medical students draw their inspiration from today's physicians, who themselves often maintain erroneous conceptions about placebos (12). As a senior physician-colleague recently put it to me, most placebos are inert, yet to do something (e.g., cause changes) they need to be anything but "inert." As a matter of fact, most placebos are inert, yet changes do occur $(13,14)$. Historically, physicians have been keenly aware that sick people get better after taking inert drugs (11). It is less evident, however, that physicians were then, as they are now, largely ambivalent about placebos (15-17).

From the outset, the road to a medical career seems congruent with reductionist science but incongruent with social science. For example, scoring highly on the Medical College Admission Test (MCAT) may make understanding placebos more difficult. The 260-minute MCAT comprises 60 minutes of "verbal reasoning," an hour-long "writing sample" and a 70-minute (54\%) even split between "physical sciences" and "biological sciences." It is apparently vital that future physicians are conversant with 17 th-century physics. In the biological sciences, biochemistry aside, the MCAT favors a knowledge of "things" (e.g., the details of prokaryotic cell transcription and translation) over an understanding of "relationships" (e.g., among predators, prey, plants, insects, and climate). Subsequently, medical education scantily draws on core issues in the social sciences and seldom addresses the complexities and subtleties of emotion, ritual, or culture. Such medical education may be advantageous for understanding causal relationships (e.g., penicillin kills bacteria), but may be less helpful when cause and effect 


\section{Text Box 1: Excerpts from Student Comments}

Below is a compilation of a few short excerpts from Placebos in Medicine students who completed the course:

"Due to its central role in medicine, not appreciating the value of placebos imposes an unfortunate limitation on both physicians and their patients. Dr. Raz's course sheds light on the how and why, while empowering students to leverage this knowledge for the ultimate well being of patients, [providing] a compelling means to achieve higher standards of care."

"I have always wondered about the art of medicine, the true fusion between science, disease knowledge, patient interaction and cure. After taking the placebo course, I [am beginning to understand] some of the complexities behind this art."

"The universality of placebos and the power of placebo effects became explicit [during the course]. I quickly realized its utility in our profession, no matter which specialty any of us would choose."

"The most important thing I have learned is that the placebo effect is everywhere; it's in the way I interact with my patients, the route of administration of the medication [I am providing], and even in the number of times I tell them to take a pill every day."

"After attending the placebo class, I changed my approach to my everyday medical interactions."

"[This elective] emphasized the importance [of] physicians having a deep understanding of the power of communication and suggestion."

"[We] learned about the complex issues of how to define the placebo effect, why some people can be more affected than others, and how placebos are significant [outside] placebo-controlled trials."

are more subtle. For example, why would a drug work twice as well in one country than in another? Why would a pill work better when it is blue than when it is red? And why do more placebos work better than few?

\section{A CHECKERED HISTORY}

Most people still construe the Latin word "placebo," as "I shall please" although this designation probably stems from a misattribution. In medieval English the term placebo took on a different meaning, referring to a sycophant who endears others with trickery rather than with substance. By the early nineteenth century a placebo referred to any medicine designed more to please than benefit the patient. Consequently, by the mid-nineteenth century it was common for people to refer to such treatments not just as "placebos" but as "mere placebos." At that time, reports described water as more effective medicine than placebos (12).

While early placebos were inert substances administered primarily to please the patients, the biological revolution of the twentieth century imbued the meaning of placebos with an unexpected twist. Considering them effective treatments, practitioners had been prescribing roborants to patients, only to learn from subsequent scientific research that their drugs were placebos (18). In more ways than one, such drugs had been prescribed not to please patients but to please doctors (16).
While anecdotal clinical trial reports comparing placebo and no-treatment groups found little evidence for placebo effects $(19,20)$, such claims have been widely critiqued (21-23), and the history of medicine is replete with placebos and abundant accounts document their therapeutic potential (11). The rise of evidencebased medicine, however, seems to have resulted in amnesia among many modern clinicians. Whereas even doctors from historical fiction know that their patients' attitudes toward medical treatment comprise a fundamental part of the healing process (24), the majority of present-day physicians are neither savvy nor conversant with research findings regarding placebos (16). Forging an interaction between biology and psychology, however, placebos elucidate many fascinating aspects of human culture and physiology $(25,26)$. They are integral to medicine and should have an important place in contemporary medical education.

\section{A PROMISING PROSPECT}

Outside of clinical trials, some physicians exclusively associate placebos with non-specific approaches such as psychotherapy and complementary and alternative medicine (CAM) (27). Many professionals, for example, inaccurately construe placebos as inevitably leading to the promotion of therapies that fall short of normal scientific standards of evaluation $(28,29)$. Whereas most CAM practices - ranging from the 
preposterous to the somewhat-plausible-but-as-yetunproven - are incongruent with scientific standards (30), placebo research is the apotheosis of marrying the sensibilities of experimental psychology with the applied value of clinical science (25).

What we think, say, and know about the world can have a dramatic influence on our physiology because culture and biology interrelate in powerful ways. Current medical education, however, may be more an impediment than an aid for grasping and leveraging placebos in medicine. Cause and effect are undeniably more tenuous in the social sciences relative to the dynamics of levers and pulleys, but to suggest a physics model of causality to our future physicians is to mislead them in ways far worse than placebos may mislead their patients.

Adding a full course on the clinical science of placebos to an overburdened medical school curriculum is a logistic challenge. It is feasible, however, to provide medical students with insights from social and cognitive psychology, medical anthropology, and other relevant social science disciplines. Placebos in Medicine was my effort to lead by example and offer interested medical students a peek into the science of placebos. It was my hope that such brief exposure would whet their research appetite, pique their intellectual curiosity and, most importantly, make them into better physicians. The students' reviews and enthusiastic response to the course's material suggest that placebo education may be sorely lacking from current medical pedagogy (see Text Box 1 for a few brief excerpts).

While medical schools have emphasized traditionally that the most important aspect of any medical experience is its content, the role of psychosocial factors and their influence on treatment is looming increasingly large. It is now evident, albeit strange and counterintuitive, that receiving - rather than the actual content of - medical treatment can initiate a healing process $(31,32)$. The medical community should engage in an open discussion regarding the relative merits and shortcomings of placebos in medicine because physicians must draw on relevant insights from the entire spectrum of science, including social science, to better heal and cure. An effective training program, therefore, must introduce future physicians to the science of placebos.

\section{REFERENCES:}

1. Waber RL, Shiv B, Carmon Z, Ariely D. Commercial features of placebo and therapeutic efficacy. Journal of the American Medical Association. 2008 March 5, 2008;299(9):1016-7.

2. Ernst E. Placebo: new insights into an old enigma. Drug Discovery Today. 2007;12(9-10):413-8.

3. Harrington A. The many meanings of the placebo effect: Where they came from, why they matter. Biosocieties. 2006;1:181-93.

4. Kaptchuk TJ. Powerful placebo: the dark side of the randomised controlled trial. Lancet. 1998 Jun 6;351(9117):1722-5.

5. Rothman KJ. Placebo mania. British Medical Journal. 1996 Jul 6;313(7048):3-4.

6. Shapiro AK, Shapiro E. The powerful placebo: from ancient priest to modern physician. Baltimore: Johns Hopkins University Press; 1997.

7. Ehni HJ, Wiesing U. International ethical regulations on placebo-use in clinical trials: a comparative analysis. Bioethics. 2008 Jan;22(1):64-74.

8. Miller FG, Kaptchuk TJ. Sham procedures and the ethics of clinical trials. Journal of the Royal Society of Medicine. 2004 December 1, 2004;97(12):576-8.

9. Thompson WG. The placebo effect and health: combining science and compassionate care. Amherst, N.Y.: Prometheus Books; 2005.

10. Kirsch I. Hidden administration as ethical alternatives to the balanced placebo design. Prevention \& Treatment. 2003 Jun;6(1): No Pagination Specified.

11. Harrington A. The placebo effect: an interdisciplinary exploration. Cambridge, Mass.: Harvard University Press; 1997.

12. Moerman DE. Meaning, medicine, and the "placebo effect". Cambridge, U.K. ; New York: Cambridge University Press; 2002.

13. Moerman DE, Jonas WB. Toward a research agenda on placebo. Advances in Mind-Body Medicine. 2000 Winter2000;16(1):33.

14. Moerman DE, Jonas WB. Deconstructing the placebo effect and finding the meaning response. Annals of Internal Medicine. 2002 Mar 19;136(6):471-6.

15. Moerman D. Doctors and patients: the role of clinicians in the placebo effect. Advances in Mind-Body Medicine. 2003 Spring;19(1):14-22.

16. Harrington A. The cure within: a history of mind-body medicine. 1st ed. New York: W.W. Norton; 2008.

17. Benedetti F. Mechanisms of placebo and placebo-related effects across diseases and treatments. Annual Review of Pharmacology and Toxicology. 2007 Jul 31.

18. Houston WR. The doctor himself as a therapeutic agent. Annals of Internal Medicine. 1938 Feb;11(8):1416-25.

19. Hrobjartsson A, Gotzsche PC. Is the placebo powerless? An analysis of clinical trials comparing placebo with no treatment. New England Journal of Medicine. 2001 May 24;344(21):1594602.

20. Hrobjartsson A, Gotzsche PC. Is the placebo powerless? Update of a systematic review with 52 new randomized trials comparing placebo with no treatment. Journal of Internal Medicine. 2004 Aug;256(2):91-100

21. Wampold BE, Imel ZE, Minami T. The story of placebo effects in medicine: Evidence in context. Journal of Clinical Psychology. 2007;63(4):379-90.

22. Wampold BE, Imel ZE, Minami T. The placebo effect: "Relatively large" and "robust" enough to survive another assault. Journal of Clinical Psychology. 2007 Apr;63(4):401-3.

23. Wampold BE, Minami T, Tierney SC, Baskin TW, Bhati KS. The placebo is powerful: Estimating placebo effects in medicine and psychotherapy from randomized clinical trials. Journal of Clinical Psychology. 2005;61(7):835-54.

24. O'Brian P. Master and commander. New York: W.W. Norton; 1990.

25. Raz A. Genetics and neuroimaging of attention and hypnotizability may elucidate placebo. International Journal of Clinical and Experimental Hypnosis. 2008;56(1):99 - 116.

26. Raz A. Hypnobo: perspectives on hypnosis and placebo. The American Journal of Clinical Hypnosis. 2007 Jul;50(1):29-36.

27. Raz A, Michels R. Contextualizing specificity: specific and nonspecific effects of treatment. The American Journal of Clinical Hypnosis. 2007 Oct;50(2):177-82. 
28. Beyerstein B. Alternative medicine: Where's the evidence? Canadian Journal of Public Health. 1997 May-Jun;88(3):14950 .

29. Beyerstein BL. Alternative medicine and common errors of reasoning. Academic Medicine. 2001 Mar;76(3):230-7.

30. Colquhoun D. Science degrees without the science. Nature. 2007 Mar 22;446(7134):373-4.
31. Kaptchuk TJ. The placebo effect in alternative medicine: can the performance of a healing ritual have clinical significance? Annals of Internal Medicine. 2002 Jun 4;136(11):817-25.

32. Kaptchuk TJ, Goldman P, Stone DA, Stason WB. Do medical devices have enhanced placebo effects? Journal of Clinical Epidemiology. 2000 Aug;53(8):786-92.

Amir Raz Ph.D., ABPH, is is the Canada Research Chair in the Cognitive Neuroscience of Attention at McGill University and the Jewish General Hospital. He holds faculty positions in the departments of Psychiatry, Neurology \& Neurosurgery, and Psychology. He received his Ph.D. in Brain Science from the Interdisciplinary Center for Neural Computation at the Hebrew University of Jerusalem. Prior to his recent transition to McGill, he has held academic positions at the Weill Medical College of Cornell University and the Columbia Medical School.

Daniella Guindi is alumnus of the Department of Psychology at McGill University. She works with Prof. Raz at the Clinical Neuroscience and Applied Cognition Laboratory in the Institute for Community and Family Psychiatry at the Jewish General Hospital. Daniella is primarily interested in understanding how the mind and body interact to impact patient health. Her interest in neuropsychology drives her to investigate aspects of hypnosis, attention and the placebo effect. She hopes to pursue a future career in medicine. 